\title{
Multiple displacement amplification as an adjunct to PCR-based detection of Staphylococcus aureus in synovial fluid
}

\author{
Sandeep Kathju ${ }^{1,2,3,4,5^{*}}$, Roger S Lasken' ${ }^{1}$, Latha Satish', Sandra Johnson ${ }^{1}$, Paul Stoodley ${ }^{6}$, J Christopher Post ${ }^{1,3,5}$, \\ Garth D Ehrlich ${ }^{1,5}$
}

\begin{abstract}
Background: Detection of bacterial nucleic acids in synovial fluid following total joint arthroplasty with suspected infection can be difficult; among other technical challenges, inhibitors in the specimens require extensive sample preparation and can diminish assay sensitivity even using polymerase chain reaction (PCR)-based methods. To address this problem a simple protocol for prior use of multiple displacement amplification (MDA) as an adjunct to PCR was established and tested on both purified S. aureus DNA as well as on clinical samples known to contain S. aureus nucleic acids.
\end{abstract}

Findings: A single round of MDA on purified nucleic acids resulted in a > 300 thousand-fold increase in template DNA on subsequent quantitative PCR (qPCR) analysis. MDA use on clinical samples resulted in at least a 100-fold increase in sensitivity on subsequent $\mathrm{QPCR}$ and required no sample preparation other than a simple alkali/heat lysis step. Mixed samples of $S$. aureus DNA with a $10^{3}-10^{4}$-fold excess of human genomic DNA still allowed for MDA amplification of the minor bacterial component to the threshold of detectability.

Conclusion: MDA is a promising technique that may serve to significantly enhance the sensitivity of molecular assays in cases of suspected joint infection while simultaneously reducing the specimen handling required.

\section{Background}

Although molecular detection of pathogens in clinical samples by PCR has been widely investigated, its reliability is still questioned in some clinical scenarios. For suspected infection following total joint arthroplasty, PCR of $16 \mathrm{~S}$ rDNA remains controversial as evidence for pathogen presence and ongoing infection. Some reports consider PCR-based techniques overly sensitive, potentially indicating DNA even in the absence of clinical criteria for infection [1]. Alternatively, it has been posited that so-called "aseptic" loosening of prostheses may be due to low-grade infection that remains difficult to detect even with molecular techniques [2], and that false-negatives may result from inefficient DNA extraction from target organisms (especially Gram-positives),

\footnotetext{
* Correspondence: skathju@wpahs.org

${ }^{1}$ Center for Genomic Sciences, Allegheny-Singer Research Institute, Allegheny General Hospital, Pittsburgh, PA, USA

Full list of author information is available at the end of the article

loss of DNA during sample processing, or the presence of PCR inhibitors in clinical samples [3].

In synovial fluid the problem of PCR inhibitors is significant, and virtually all studies evaluating orthopedic joint infections with PCR techniques have first undertaken some means of isolating genomic DNA from the clinical specimens [eg. [4-6]]. van der Heijden et al., for example, employed a lysis buffer containing SDS and proteinase $\mathrm{K}$ at $60 \mathrm{C}$ for 18 hours, followed by phenol extraction and ethanol precipitation, but found that additional purification with a QIAamp blood kit (Qiagen) was still necessary [7]. As a result of these various concerns, PCR-based analysis of clinical joint aspirates is not typically used as an aide to clinical decision-making when confronted with a possibly infected joint prosthesis.

A growing body of evidence supports the theory that chronic prosthetic joint infections arise from bacterial biofilms associated with the implants. Biofilm bacteria are notoriously difficult to culture and highly resistant 
to conventional antibiotic therapy. Treatment of the infected implant often requires explantation, inflicting significant morbidity and entailing significant expense; surgeons are understandably reluctant to undertake such a course without good reason, but standard bacterial culture of diagnostic aspirates is usually negative. When culture results are positive, $S$. aureus is the most frequently recovered organism in chronic joint implant infections, although numerous unusual bacterial species have also been implicated [8]. It would be an important advance to establish a diagnostic protocol for such infections that reliably improved sensitivity with a minimum of specimen handling.

We have used multiple displacement amplification (MDA) $[9,10]$ to improve PCR detection of bacterial DNA present in clinical samples using $S$. aureus as a test organism. MDA amplifies all DNA content in a sample including human and bacterial DNA [11,12]. It facilitates subsequent PCR detection of bacteria by 1 ) enriching DNA relative to PCR inhibitors (such as hemoglobin and nucleases), 2) generating abundant DNA template with less incidence of mutational error than PCR amplification where low bacterial counts provide only suboptimal amounts of DNA, and 3) providing a large source of DNA to carry out replicate PCR assays, repeat assays to confirm results, interrogate an unlimited number of genomic loci and any pathogen within a mixed sample, and archive DNA for genomic sequencing or other detailed studies. MDA is simple to employ and requires no specialized equipment. Thus it may be extremely useful in investigating complex clinical samples containing comparatively small quantities of target organisms.

\section{Methods}

\section{Quantitative PCR assay for S. aureus gene loci}

In order to quantify the effect MDA can have, we first established and validated a quantitative real-time PCR assay for several single copy (not rDNA) gene loci in $S$. aureus: lysS and proS. The primers and probes used are listed in Table 1. $50 \mu \mathrm{l}$ PCR reactions (containing varying concentrations of $S$. aureus genomic DNA) used denaturation at $95 \mathrm{C} \times 10 \mathrm{~min}$; then 2 -stage PCR at $95 \mathrm{C}$ $\times 15 \mathrm{sec}$, and $60 \mathrm{C} \times 1 \mathrm{~min} \times 40$ cycles total, with $0.5 \mu \mathrm{l}$

Table 1 Primer and probe sequences used in qPCR assays for lysS and pros

\begin{tabular}{ll}
\hline lyss primers & 5'-GTCGTTTTGAAGCGCAACTT-3' \\
\hline lyss probe & 5'-CCTGTCGGAGGCATACCATA-3' \\
\hline proS primers & 5'-GGCATTAAGTGCTATCGGTGA-3' \\
& 5'-AAAGGTTGCACAGTAGAATGCTT-3' \\
\hline pros probe & 5'-GAAAAAGCAGAAGTCGTTTACGAACC-3' (6-FAM) \\
\hline
\end{tabular}

Platinum Taq polymerase (Invitrogen), $1 \times$ PCR buffer, $5 \mathrm{mM} \mathrm{MgCl}_{2}$, dNTPs at $1 \mathrm{mM}$, primers and Taqman probe at $500 \mathrm{nM}$, and $1 \mu \mathrm{l}$ of Rox reference dye. Assays were performed in an ABI 7900HT Sequence Detection System and critical cycle values were determined with the manufacturer's software.

\section{Quantitation of purified S. aureus DNA after pre- treatment with MDA}

We first investigated the effect of MDA on purified genomic DNA using the GenomiPhi MDA kit (GEHealthcare). Varying amounts of $S$. aureus DNA (isolated as per [13] from reference strain Seattle 1945, ATCC\# 25923) from $0.01 \mathrm{ng}$ to $100 \mathrm{ng}$ were assayed using the qPCR assays described above and a standard curve was established. $0.01 \mathrm{ng}$ of genomic $S$. aureus DNA were also pre-incubated with $1 \mu \mathrm{l}$ of the GenomiPhi enzyme for 16 hours at $30 \mathrm{C}$ in $100 \mu \mathrm{l}$ volume (as per the manufacturer's specifications). A corresponding control reaction lacking only the GenomiPhi enzyme itself was also carried out. $5 \mu \mathrm{l}$ of the resulting material (effectively a $1 / 20$ dilution) were then assayed for DNA content by qPCR as described above.

\section{Assay for S. aureus DNA in clinical samples using MDA}

MDA was next tested for S.aureus DNA in synovial fluid from an elbow total joint arthroplasty patient where infection was suspected but could not be confirmed by standard microbiology despite two years of recurrent symptoms and multiple surgical and medical interventions. We previously reported that bacteria in biofilm configuration were observed in aspirate, tissue, and cement samples from this patient by confocal microscopy, and that PCR and reverse-transcriptase PCR detected intact $S$. aureus (but not $S$. epidermidis) DNA and mRNA respectively in purified nucleic acids from the synovial fluid aspirate [14]. Two discrete samples were now subjected to qPCR analysis with and without pre-treatment with MDA.

Elbow synovial fluid aspirate obtained with sterile technique was placed either in RNAlater solution or in a microfuge tube directly, then snap frozen in dry/ice ethanol and preserved at $-70 \mathrm{C}$ until further processing. On thawing, $0.1 \mu \mathrm{l}, 1 \mu \mathrm{l}$, or $10 \mu \mathrm{l}$ of stored aspirate was brought to a volume of $27 \mu \mathrm{l}$ with phosphate buffered saline (PBS), then lysed by addition of $1 / 10 \mathrm{vol}(3 \mu \mathrm{l})$ of $400 \mathrm{mM} \mathrm{KOH}, 10 \mathrm{M}$ EDTA with incubation at $65 \mathrm{C} \times 3$ minutes. The lysates were then neutralized by addition of $3 \mu \mathrm{l}$ of $800 \mathrm{mM}$ Tris- $\mathrm{HCl}(\sim \mathrm{pH} 4)$, for a total volume of $33 \mu \mathrm{l}$. As controls, the same volumes of stored aspirate $(0.1,1$ and $10 \mu \mathrm{l})$ were brought directly to $33 \mu \mathrm{l}$ with added PBS and were not lysed. Samples to undergo MDA had $67 \mu \mathrm{l}$ of MDA mix added, comprised of $25 \mu \mathrm{l} 4 \times$ MDA master mix, $41 \mu \mathrm{l}$ water, and $1 \mu \mathrm{l}$ of 
Phi 29 enzyme. Control samples that were not to undergo MDA were prepared similarly, except with 42 $\mu \mathrm{l}$ of water and no GenomiPhi DNA polymerase. All samples were incubated at $30 \mathrm{C} \times 16$ hours, then at $65 \mathrm{C}$ $\times 3$ minutes (to deactivate the DNA polymerase) before being stored at 4C. $20 \mu \mathrm{l}$ aliquots were then used in qPCR as described above (biological duplicates of each assay condition gave identical results).

\section{Quantitation of S. aureus DNA and human genomic DNA in aspirate samples}

Total nucleic acids were isolated from two discrete samples of elbow aspirate fluid as per Stoodley et al. [14]. This material was then used as substrate for direct quantitation of $S$. aureus DNA by real-time PCR with the proS and lysS assays described above and in Table 1 . The quantity of human genomic DNA contained was determined by quantitative PCR for human GAPDH using Gene Expression Assays from Applied Biosystems (Foster City, CA); assay numbers are Hs02786624-g1 and Hs03929097-g1.

\section{Assay for S. aureus DNA in samples of mixed human and bacterial DNA}

$0.01 \mathrm{ng}$ of purified S. aureus DNA was mixed with increasing amounts (0 ng to $100 \mathrm{ng}$ ) of purified human genomic DNA. These mixes underwent MDA using the GenomiPhi V2 DNA Amplification kit (GE Healthcare, cat. \# 25-6600-30) as per the manufacturer's instructions. Briefly, mixes containing $0.01 \mathrm{ng}$ of $S$. aureus DNA with varying quantities of human DNA were brought to $10 \mu \mathrm{l}$ in Sample Buffer, then heat denatured at $95 \mathrm{C} \times 3 \mathrm{~min}$, then placed on ice. $10 \mu \mathrm{l}$ of Master Mix (including reaction buffer and enzyme) were added to each sample and allowed to incubate at $30 \mathrm{C} \times 1.5 \mathrm{hrs}$. The enzyme was then inactivated at $65 \mathrm{C} \times 10 \mathrm{~min}$, then cooled to $4 \mathrm{C}$. Control reactions lacking only the GenomiPhi enzyme were also run. $1 \mu$ l of the final reaction products were then diluted 1:100 in TE, and these diluted products were then used in qPCR assays for $S$. aureus with the lys and proS loci as described above.

\section{Results}

We first established a qPCR assay for $S$. aureus based on the single copy loci lys $\mathrm{S}$ and proS. qPCR of both target genes yielded amplimers of the expected molecular weight on gel electrophoresis (data not shown) and showed a direct correlation between critical cycle threshold and substrate concentration. Appropriate sigmoidal curves for amplimer accumulation were observed in all instances.

We next determined what degree of amplification might be afforded by MDA on the naked DNA template used to validate our S. aureus-specific assays. Pre-incubation with the GenomiPhi enzyme resulted in a vast increase in the amount of target $S$. aureus DNA present, reducing the threshold critical cycle from $\sim 31.7$ to $\sim 16.9$. This represents a theoretical amplification (assuming a two-fold exponential increase with each cycle reduced, and allowing for the 20-fold dilution introduced for experimental purposes) of $>2^{14} \times 20$, or over 300 thousand-fold (Table 2 ).

We next examined what effect MDA pre-treatment would have on clinical samples of joint aspirates recovered from a well-characterized infected patient after total elbow arthroplasty; both samples stored in RNAlater and also snap-frozen directly were tested. In order to make available DNA for amplification without need for extensive specimen handling, a simple protocol for alkali/heat lysis was introduced. Results are shown in Table 3.

When aspirate samples were unlysed there was no signal accumulation above the detection threshold, consistent with the presence of inhibitors since these same materials have yielded PCR amplimers successfully after purification of nucleic acids within. Aspirate stored in RNA later as well as stored directly, when lysed, did give a positive signal on direct qPCR assay but only when $0.1 \mu \mathrm{l}$ of material was used, not when greater quantities of starting material were present, again consistent with the presence of inhibitors. In contrast, all lysed aspirates subjected to MDA gave convincingly positive qPCR signals for both proS and lysS, demonstrating that pre-amplification with MDA expands the window of detectability in these joint aspirate samples by at least 100 -fold (from $0.1 \mu \mathrm{l}$ to $10 \mu \mathrm{l}$ inclusive). Use of RNAlater as a storage medium had no effect on the initial detection or ultimate amplification yield.

We next used real-time PCR to quantify the amount of $S$. aureus and human genomic DNA present in

\section{Table 2 Quantitation of S. aureus genomic DNA (gDNA)} by real time PCR

\begin{tabular}{|c|c|c|c|c|}
\hline MDA & S. aur gDNA & Probe & Average Ct & SEM ( \pm$)$ \\
\hline $\mathrm{N}$ & $100 \mathrm{ng}$ & pros & 17.8 & 0.03 \\
\hline $\mathrm{N}$ & 10 ng & pros & 22.1 & 0.05 \\
\hline $\mathrm{N}$ & $1 \mathrm{ng}$ & pros & 24.6 & 0.03 \\
\hline $\mathrm{N}$ & $0.1 \mathrm{ng}$ & pros & 27.7 & 0.06 \\
\hline $\mathrm{N}$ & $0.01 \mathrm{ng}$ & pros & 31.7 & 0.26 \\
\hline $\mathrm{N}$ & $0 \mathrm{ng}$ & pros & U & U \\
\hline$(\mathrm{N})$ & $0.01 \mathrm{ng}$ & pros & 35.4 & 0.85 \\
\hline$(Y)$ & $0.01 \mathrm{ng}$ & pros & 16.9 & 0.05 \\
\hline
\end{tabular}

Triplicate samples of isolated S. aureus genomic DNA were assayed by qPCR; the calculated average threshold critical cycle $(\mathrm{Ct})$ values are provided, as is the standard error. Each sample concentration gave a highly reproducible result; the data shown are using the proS probe, but equivalent results were obtained using lysS. Pre-treatment of $S$. aureus gDNA by MDA resulted in a massive reduction in $\mathrm{Ct}$, indicating a massive amplification of template. In MDA control lacking the DNA polyermase, Ct actually slightly increased, due to dilution of the starting material. $0 \mathrm{ng}$ of gDNA (negative control) gave no detectable signal ( $\mathrm{Ct}$ undetermined, represented as " $\mathrm{U}$ " above). 
Table 3 qPCR assay of aspirated synovial fluid, + /- lysis and MDA

\begin{tabular}{ccccc}
\hline Sample vol. & Probe & Lysis -, MDA - & Lysis +, MDA - & Lysis +, MDA + \\
\hline $0.1 \mu \mathrm{l}$ & proS & $\mathrm{U}$ & + & + \\
$1.0 \mu \mathrm{l}$ & proS & $\mathrm{U}$ & $\mathrm{U}$ & + \\
$10 \mu \mathrm{l}$ & proS & $\mathrm{U}$ & $\mathrm{U}$ & + \\
$0.1 \mu \mathrm{l}$ & proS & $\mathrm{U}$ & + & + \\
$1.0 \mu \mathrm{l}$ & proS & $\mathrm{U}$ & $\mathrm{U}$ & + \\
$10 \mu \mathrm{l}$ & proS & $\mathrm{U}$ & $\mathrm{U}$ & + \\
$0.1 \mu \mathrm{l}$ & lysS & $\mathrm{U}$ & + & + \\
$1.0 \mu \mathrm{l}$ & lysS & $\mathrm{U}$ & $\mathrm{U}$ & + \\
$10 \mu \mathrm{l}$ & lysS & $\mathrm{U}$ & $\mathrm{U}$ & + \\
$0.1 \mu \mathrm{l}$ & lysS & $\mathrm{U}$ & + & + \\
$1.0 \mu \mathrm{l}$ & lysS & $\mathrm{U}$ & $\mathrm{U}$ & + \\
$10 \mu \mathrm{l}$ & lysS & $\mathrm{U}$ & $\mathrm{U}$ & +
\end{tabular}

Varying volumes of joint aspirate were treated as per the conditions listed atop each column, either with or without lysis and MDA. "U" indicates that no critical cycle value was obtained (undetermined), and thus that no template DNA was detected. " + " indicates that a valid $\mathrm{Ct}$ value was obtained, and an appropriate sigmoidal accumulation curve, indicating successful detection of template. Results were identical in two samples of aspirate, using the proS and lysS probes.

synovial fluid samples. Assaying two independently obtained samples from the same patient, we found that $S$. aureus DNA was present at $0.014 \mu \mathrm{g} / \mathrm{ml}$ in one sample, and at $0.020 \mu \mathrm{g} / \mathrm{ml}$ in the other. Human genomic DNA was present in over a thousand-fold excess by comparison, measured at $33.6 \mu \mathrm{g} / \mathrm{ml}$ and $79.4 \mu \mathrm{g} / \mathrm{ml}$ respectively.

In order to verify that MDA could function to amplify minor quantities of bacterial DNA in the presence of large (but physiologically relevant) quantities of human DNA, we next mixed small quantities of purified $S$. aureus DNA (in roughly the quantity we would expect to find in a small volume of synovial fluid) with increasing amounts of purified human genomic DNA. Samples were either treated +/- MDA; the resulting mixes were diluted and then assayed by quantitative PCR. Results are shown in Table 4.

Using $0.01 \mathrm{ng}$ of $S$. aureus DNA as a starting template, we were unable to detect any accumulation signal in our real-time assay under any condition when pre-treatment with MDA had not been applied. In contrast, when pretreatment with MDA was effected, all samples gave convincing positive results, despite the additional dilution. Results were uniformly positive when up to $10 \mathrm{ng}$ of human DNA were in the initial mix, representing a thousand-fold excess. Results were still mostly positive, in 10 out of 12 trials, when $100 \mathrm{ng}$ of human DNA were in the initial template mix, raising the possibility that a $>10^{4}$ fold excess of human DNA may itself begin to exert some inhibitory effect on the ability of MDA to amplify minor bacterial components in the mix. However, in
Table 4 qPCR assay of purified S. aureus and human DNA (hDNA) mix, with and without MDA pre-treatment

\begin{tabular}{|c|c|c|c|}
\hline Sample & Probe & MDA - & $\mathrm{MDA}+$ \\
\hline 0.01 ng S. aur + 100 ng hDNA & pros & U & $+^{*}(10 / 12)$ \\
\hline 0.01 ng S. aur + 10 ng hDNA & pros & $U$ & $+(12 / 12)$ \\
\hline $0.01 \mathrm{ng}$ S. aur +1 ng hDNA & pros & U & $+(12 / 12)$ \\
\hline 0.01 ng S. aur + 0 ng hDNA & pros & U & $+(12 / 12)$ \\
\hline
\end{tabular}

Ct values were undetermined (U) for $S$. aureus DNA without MDA pretreatment. In contrast, " + " indicates the successful detection of target template, demonstrating that MDA had successfully increased the $S$. aureus component to the level of detection; the numbers at right in parentheses represent the number of successful amplification attempts/number of total attempts. When $100 \mathrm{ng}$ of human genomic DNA were used, in 2 out of 12 attempts no signal detection was observed although results were positive for the majority of trials, thus prompting a " $+^{* "}$ notation, with the possibility that this amount of excess background DNA may become partly inhibitory to the MDA.

general these results support our direct evidence from the clinical samples that MDA has the potential to be a useful adjunct to PCR examination of synovial aspirates with its ability to amplify small quantities of bacterial DNA in complex mixes.

\section{Discussion}

The technique of multiple displacement amplification relies on the unique properties of the Phi29 DNA polymerase, which generates copies of its template DNA with great fidelity; the calculated error rate of the Phi29 polymerase is $3 \times 10^{-6}$, almost two orders of magnitude superior to that of Taq polymerase. The Phi29 catalyzed reaction proceeds isothermally through a mechanism of strand displacement, and the enzyme is highly processive, typically incorporating $>70,000 \mathrm{bp}$ per binding event [15]. These features, markedly different from those of PCR-based amplification, make MDA a potentially useful adjunct to quantitative PCR assays without being subject to the same technical pitfalls as PCR.

MDA has been used for a variety of purposes from a number of sample types. MDA improved sensitivity of PCR detection of rare Wolbachia cells in mites by $10^{2}$ $10^{7}$-fold [16]. Genomic DNA was amplified by MDA from lepromatous human tissue, improving the success of microsatellite analysis of Mycobacterium leprae from $20 \%$ to $92 \%$ for these highly degraded archived samples [17]. It has been successfully used to amplify whole genome DNA from a wide variety of clinical specimens [11] and from very limited numbers of cells or even single cells [18-20].

This report represents (to our knowledge) the first application of MDA to diagnostic challenges within the orthopedic realm. Although our study focused on S. aureus, MDA will amplify all DNAs in a complex mixture in a relatively unbiased manner and, thus, should prove equally useful for detection of other pathogens or poly-microbial infections. MDA will not distinguish 
between DNA from lysed cells versus DNA from intact microorganisms, thus, positive results are not necessarily indicative of bacterial viability, but in the setting of (putatively sterile) synovial fluid any evidence of bacterial DNA may be regarded as abnormal.

The protocol we describe requires only a brief lysis step, obviating the need for any subsequent lengthy nucleic acid purification, and MDA itself demands no specialized equipment or complicated handling. Potentially, the processing required for assay of clinical synovial fluid/aspirates might be minimized even further, although a more expanded and detailed study will be needed to confirm this, as well as to test MDA in a larger number of samples. Although our initial MDA protocol required a 16 hour incubation, a newer commercially available MDA kit (GE Healthcare) requires only 1.5 2 hours, possibly bringing even closer the goal of a simple, speedy and reliable PCR-based molecular assay for orthopedic joint infections.

\section{Conclusion}

MDA is a promising technique that may serve to significantly enhance the sensitivity of molecular assays in cases of suspected joint infection while simultaneously reducing the specimen handling required.

\section{Acknowledgements}

We would like to thank Dr. Mark Baratz for assistance in obtaining the clinical material tested. We wish to thank Ms. Mary OToole for her assistance in the preparation of this manuscript. This work was supported in part by National Institutes of Health research grants DE014780 (SK) and DC04173 (GDE). RSL was funded by a grant from the National Human Genomic Research Institute, NIH.

\section{Author details}

${ }^{1}$ Center for Genomic Sciences, Allegheny-Singer Research Institute, Allegheny General Hospital, Pittsburgh, PA, USA. ${ }^{2}$ Division of Oral/Maxillofacial Surgery, Allegheny General Hospital, Pittsburgh, PA, USA. ${ }^{3}$ Division of Otolaryngology/ Head and Neck Surgery, Allegheny General Hospital, Pittsburgh, PA, USA.

${ }^{4}$ Division of Plastic Surgery, Allegheny General Hospital, Pittsburgh, PA, USA. ${ }^{5}$ Department of Microbiology and Immunology, Drexel University College of Medicine, Allegheny Campus, Pittsburgh, PA, USA. ' National Center for Advanced Tribology at Southampton (nCATS), University of Southampton, Highfield, Southampton, SO17 1BJ, UK.

\section{Authors' contributions}

SK, RL, and PS designed the study. SK, LS, and SJ performed the molecular analyses on all samples. SK, RL, LS, JCP and GDE analyzed and interpreted the data. SK, RL, and PS wrote the manuscript. All authors read and approved the final manuscript.

\section{Competing interests}

The authors declare that they have no competing interests.

Received: 17 August 2009 Accepted: 13 October 2010 Published: 13 October 2010

\section{References}

1. Hoeffel DP, Hinrichs SH, Garvin KL: Molecular diagnostics for the detection of musculoskeletal infection. Clin Orthop Relat Res 1999, 360:37-46.

2. Tunney MM, Patrick S, Curran MD, Ramage G, Hanna D, Nixon JR, Gorman SP, Davis RI, Anderson N: Detection of prosthetic hip infection at revision arthroplasty by immunofluorescence microscopy and PCR amplification of the bacterial 16S rRNA gene. J Clin Microbiol 1999, 37:3281-3290

3. Trampuz A, Osmon DR, Hanssen AD, Steckelberg JM, Patel R: Molecular and antibiofilm approaches to prosthetic joint infection. Clin Orthop Relat Res 2003, 414:69-88.

4. Mariani BD, Martin DS, Levine MJ, Booth RE Jr, Tuan RS: Polymerase chain reaction detection of bacterial infection in total knee arthroplasty. Clin Orthop Relat Res 1996, 331:11-22.

5. Mariani BD, Levine MJ, Booth RE Jr, Tuan RS: Development of a novel, rapid processing protocol for polymerase chain reaction-based detection of bacterial infections in synovial fluids. Mol Biotechnol 1995, 4:227-237.

6. Tarkin IS, Henry TJ, Fey PI, Iwen PC, Hinrichs SH, Garvin KL: PCR rapidly detects methicillin-resistant staphylococci periprosthetic infection. Clin Orthop Relat Res 2003, 414:89-94.

7. van der Heijden IM, Willbrink B, Vije AEM, Schouls LM, Breedveld FC, Tak PP: Detection of bacterial DNA in serial synovial samples obtained during antibiotic treatment from patients with septic arthritis. Arthritis Rheum 1999, 42:2198-2203.

8. Fenollar F, Roux V, Stein A, Drancourt M, Raoult D: Analysis of 525 samples to determine the usefulness of PCR amplification and sequencing of the $16 \mathrm{~S}$ rRNA gene for diagnosis of bone and joint infections. J Clin Microbiol 2006, 44:1018-28.

9. Dean FB, Nelson JR, Giesler TL, Lasken RS: Rapid amplification of plasmid and phage DNA using Phi 29 DNA polymerase and multiply-primed rolling circle amplification. Genome Res 2001, 11:1095-1099.

10. Dean FB, Hosono S, Fang L, Wu X, Faruqi AF, Bray-Ward P, Sun Z, Zong Q Du Y, Du J, Driscoll M, Song W, Kingsmore SF, Egholm M, Lasken RS: Comprehensive human genome amplification using multiple displacement amplification. Proc Natl Acad Sci USA 2002, 99:5261-5266.

11. Hosono S, Faruqi AF, Dean FB, Du Y, Sun Z, Wu X, Du J, Kingsmore SF, Egholm M, Lasken RS: Unbiased whole-genome amplification directly from clinical samples. Genome Res 2003, 13:954-964.

12. Lasken RS, Egholm M: Whole genome amplification: abundant supplies of DNA from precious samples or clinical specimens. Trends Biotechnol 2003, 21:531-535.

13. Stoodley P, Kathju S, Hu FZ, Erdos G, Levenson JE, Mehta N, Dice B, Johnson S, Hall-Stoodley L, Nistico L, Sotereanos N, Sewecke J, Post JC, Ehrlich GD: Molecular and imaging techniques for bacterial biofilms in joint arthroplasty infections. Clin Orthop Relat Res 2005, 437:31-40.

14. Stoodley P, Nistico L, Johnson S, Lasko LA, Baratz M, Gahlot V, Ehrlich GD, Kathju S: Direct demonstration of viable Staphylococcus aureus biofilms in an infected total joint arthroplasty. J Bone Joint Surg Am. Aug 2008, 90(8):1751-8.

15. Luthra $R$, Medeiros $L$ : Isothermal multiple displacement amplification: a highly reliable approach for generating unlimited high molecular weight genomic DNA from clinical specimens. J Mol Diagn. Aug 2004, 6(3):236-42.

16. Jeyaprakash A, Hoy MA: Multiple displacement amplification in combination with high-fidelity PCR improves detection of bacteria from single females or eggs of Metaseiulus occidentalis. J Invertebr Pathol 2004, 86:111-116.

17. Groathouse NA, Brown SE, Knudson DL, Brennan PJ, Slayden RA: Isothermal amplification and molecular typing of the obligate intracellular pathogen Mycobacterium leprae isolated from tissues of unknown origins. J Clin Microbiol 2006, 44:1502-1508.

18. Ishoey T, Woyke T, Stepanauskas R, Novotny M, Lasken RS: Genomic sequencing of single microbial cells from environmental samples. Curr Opin Microbiol Jun 2008, 11(3):198-204.

19. Lasken RS: Single-cell genomic sequencing using Multiple Displacement Amplification. Curr Opin Microbiol 2007, 10:510-516.

20. Raghunathan A, Ferguson HR, Bornarth CJ, Driscoll M, Lasken RS: Genomic DNA amplification from a single bacterium. Appl Environ Microbiol 2005, 71:3342-3347.

doi:10.1186/1756-0500-3-259

Cite this article as: Kathju et al:: Multiple displacement amplification as an adjunct to PCR-based detection of Staphylococcus aureus in synovial fluid. BMC Research Notes 2010 3:259. 